\title{
LA POLÍTICA DE COMERCIO EXTERIOR Y LAS EXPORTACIONES COLOMBIANAS
}

José Jaime Baena Rojas

DOI: https://doi.org/10.18601/01245996.v21n41.03. Recepción: 21-112017, modificación final: 02-04-2019, aceptación: 14-05-2019. Sugerencia de citación: Baena R., J. J. (2019). La política de comercio exterior y las exportaciones colombianas. Revista de Economia Institucional, 21(41), 51-70.

a Doctor en Derecho y Ciencia Política. Profesor-investigador, Institución Universitaria CEIPA, Medellín, Colombia, [jose.baena@ceipa.edu.co], [https://orcid.org/0000-0002-0915-4087]. 


\section{La política de comercio exterior y las exportaciones colombianas}

Resumen Este artículo analiza el comercio exterior colombiano desde la apertura económica y el ingreso a la OMC en 1995 hasta 2016. Identifica los principales productos exportados así como también su importancia en el comercio internacional con base en datos de la Dian, el Dane, de la OMC y el ITC. De este modo, muestra que las exportaciones colombianas dependen de productos mineros, principalmente hidrocarburos y carbón, aunque también exporta algunos bienes agrícolas -flores, café y banano- con buenos lugares en los mercados internacionales pero baja participación en las exportaciones totales del país.

Palabras clave: comercio exterior, exportaciones, balanza comercial, Colombia; JEL: D10, F10

\section{The foreign trade policy and Colombian exports}

Abstract This article develops an analysis of foreign trade in Colombia since its economic opening and entry into the WTO in 1995 until 2016. In addition, the main products exported in this country are identified besides their influence in international trade. Then, a review of local databases such as Dian, Dane among other international ones such as the WTO and ITC is carried out. It is concluded that Colombia's foreign trade depends on mining since the country exports mainly hydrocarbons and coal; Also, although the country exports agricultural goods such as flowers, coffee and bananas that play a leading role in international trade, these are not yet decisive for the total exports of the country.

Keywords: Foreign trade, exports, trade balance, Colombia; JEL: D10, F10

\section{A política de comércio exterior e as exportações colombianas}

Resumo Este artigo analisa o comércio exterior da Colômbia desde a abertura econômica e a entrada na Organização Mundial do Comércio (OMC), em 1995, até 2016. Ele identifica os principais produtos exportados, bem como sua importância no comércio internacional com base em dados da Direção de Impostos e Alfândegas Nacionais (Dian), do Departamento Administrativo Nacional de Estatística (Dane), da OMC e do Centro de Comércio Internacional. Além disso, mostra que as exportações colombianas dependem de produtos de mineração, principalmente, hidrocarbonetos e carvão, embora também exporte alguns produtos agrícolas - flores, café e banana - com bom posicionamento nos mercados internacionais, mas baixa participação no total das exportações do país.

Palavras-chaves: comércio exterior, exportações, balança comercial, Colômbia; JEL: D10, F10 
$\mathrm{D}$ esde el ingreso de Colombia a la Organización Mundial de Comercio (OMC) a mediados de los años noventa ha sido evidente el crecimiento anual de las exportaciones, y la liberalización del comercio parece haber traído una serie de beneficios para el comercio exterior en algunos rubros. Aunque dicha liberalización ha llevado a enfrentar retos difíciles por la libre competencia a la que se ha expuesto el país; debido en principio a la evolución y la dinámica de la globalización promovida por el sistema multilateral de comercio, el sistema monetario internacional y el sistema financiero global. Todo ello dentro del nuevo paradigma de comercio internacional que comenzaba a consolidarse en ese entonces.

Es preciso entonces señalar que este proceso o cambio de modelo en la política de comercio exterior no fue precisamente un ejercicio político de libre autonomía. Según Londoño (1998), la apertura económica basada en principios neoliberales, que promueve la iniciativa individual y privada y la libre competencia en el mercado, se presentó como un modelo imprescindible sin el cual América Latina no podría superar el subdesarrollo socioeconómico, el cual presuntamente obedecía a las políticas proteccionistas adoptadas por muchos países de la región.

Colombia registró un comportamiento económico destacado en la década de 2005 a 2015 promovido por el boom del petróleo y de la minería. El aumento de la inversión extranjera directa en el sector de materias primas, los tratados de libre comercio y la reducción de las barreras al comercio, el acierto de algunas políticas financieras y otros tantos aspectos más favorecieron el comportamiento de la economía. Pero esto no ha significado un desarrollo real, ya que la productividad y la inversión en sectores diferentes del petróleo y la minería han sido insuficientes debido a la fuerte carga tributaria a la inversión y la contratación laboral, así como a problemas de infraestructura y de acceso a financiación (Ocde, 2015).

Históricamente, la elección entre políticas proteccionistas o de libre cambio ha generado fuertes discusiones. Algunos autores hoy sostienen que, en Colombia y muchos otros países de la región, la productividad se ha deteriorado debido al cambio de modelo de desarrollo industrial que se venía implementando por el de la apertura económica y a que el nuevo escenario del comercio exterior obligó a que muchas empresas nacionales compitieran sin tener aún capacidad suficiente (Ortiz, Uribe y Vivas, 2013). Además, que se han creado nuevas dependencias, no solo en la exportación de bienes de consumo y materias primas sino en la procedencia de los bienes de exportación, 
pues solo algunas regiones han logrado elevar sus exportaciones, mientras que otras que se han quedado estancadas (Montoya, 2013).

Este artículo expone algunas consideraciones sobre el desarrollo de la política de comercio exterior del país. En la primera sección se revisan aspectos de la discusión sobre el papel de la apertura económica y sus efectos para las exportaciones. En la segunda sección se describe la manera de analizar la información recogida de diversas fuentes nacionales e internacionales. En la tercera sección se exponen los resultados y se analiza el comportamiento del comercio exterior colombiano; se identifican las empresas con mayor participación en las exportaciones, el volumen de exportaciones por departamentos, los productos más exportados, el comportamiento de las exportaciones desde la apertura económica desde 1995, la participación de las exportaciones por sectores y la participación de algunos bienes de exportación -materias primas mineras y agrícolas, y productos terminados en el total de exportaciones mundiales. En la última sección se presentan las conclusiones y algunas reflexiones sobre la política de exportación del país.

\section{MARCOTEÓRICO}

\section{POLÍTICA DE COMERCIO EXTERIOR Y EXPORTACIONES DESDE LA APERTURA ECONÓMICA}

En 1991 Colombia experimentó uno de los momentos más importantes de su historia política reciente con la aprobación de la nueva Constitución política, aún vigente, entre otras razones por la necesidad de adaptarse a las nuevas circunstancias internacionales, entre ellas la influencia del pensamiento neoliberal condensado en los lineamientos y el paquete de reformas del Fondo Monetario Internacional, el Banco Mundial y el Departamento del Tesoro de Estados Unidos, conocido como el Consenso de Washington, que produjo grandes cambios en la vida política, social y económica de Colombia y otros países latinoamericanos, con agudos problemas de deuda internacional (Cruz, 2010).

Según Moncayo (2003) este sobresaliente momento de la historia constitucional del país fue producto de una fuerte coacción, al menos en materia económica, ejercida por ciertos grupos internacionales y las mismas disposiciones del Consenso de Washington que no dejaban una alternativa distinta excepto quizás el aislamiento comercial. Debido a ella los países latinoamericanos tuvieron que implementar una serie de políticas comerciales como la privatización de las empresas 
públicas, la integración al mercado mundial y la supresión de medidas intervencionistas que impedían el libre funcionamiento del mercado. Pero sus resultados parecen no haber sido los mejores en los países andinos y generaron problemas de orden político e institucional como de atraso tecnológico.

Así, cabe decir que en países como Colombia la toma de decisiones en la formulación y ejecución de la política exterior siempre ha estado supeditada a las relaciones comerciales con otros países y a otros factores, como la presión de los gremios económicos. Esto ha llevado a ejecutar políticas públicas como los programas de transformación productiva, para promover el progreso técnico, el crecimiento económico y objetivos tales como diversificar la oferta exportable con alto valor agregado, crear ciertos sectores y consolidarlos a nivel mundial y mejorar la productividad empresarial, que no han funcionado a cabalidad, debido a que aún dependen de la exportación de productos primarios y es manifiesta la gran lentitud en la ejecución de las políticas de transformación productiva (López y Montoya, 2016).

Es evidente que, pese al complejo momento político de la reforma constitucional, desde un principio, con la apertura económica, Colombia adoptó políticas de comercio exterior para liberalizar el comercio y buscar nuevas relaciones comerciales con otros países; y en especial para adaptar el modelo político institucional al modelo internacional establecido por la globalización, pues de otro modo podría haber llevado al aislamiento comercial (Juárez, 1993).

Pese a las reformas estructurales y a las nuevas políticas de comercio, el estado de la economía es hasta ahora particularmente vulnerable, y no se ha logrado una transformación visible del aparato productivo para afrontar de manera contundente los desafíos de la liberalización comercial y la apertura económica (Garay, 1998, p. 71).

Es claro que el aislamiento comercial hipotético no habría sido la solución debido a que mucho más de dos tercios de los estados existentes en el mundo hoy hacen parte de la OMC, reconociendo así las posibilidades que ofrece el sistema multilateral de comercio; y a que el crecimiento total de las exportaciones colombianas en las últimas décadas ha sido significativo. En todo caso, el país ha estado supeditado al comportamiento del sector minero y se han intensificado los problemas de falta de diversificación y desindustrialización (López, López y Montes, 2015; Baena y Fernández, 2016).

Díaz (2014) muestra que el comercio exterior colombiano se ha basado, durante años, en la explotación de recursos naturales y mineros, entre los que se destacan los hidrocarburos, el carbón y el 
ferroníquel; así como de productos agrícolas: flores, café y banano. Debido, en principio, a que las dotaciones relativas de los factores relativamente abundantes (trabajo y tierra) han sido sumamente determinantes y a que el mismo país sigue manteniendo una estrecha relación comercial con América y Europa pero muy pocas con otros continentes, especialmente Asia, pese a la gran caída de los precios del transporte, el desarrollo de la tecnología en comunicaciones y la tendencia mundial a reducir las barreras arancelarias.

Con independencia de que la dinámica del comercio exterior colombiano obedezca a la adopción de políticas neoliberales o a la disponibilidad de recursos y de factores relativamente abundantes, en el país se ha creado una dependencia sustancial del sector primario, que genera poco valor agregado, la cual se acentuó con el incremento de los precios internacional de estas materias primas. Hoy, la caída de los precios ha afectado el crecimiento de las exportaciones (Jacobs, 2015; Unctad, 2017).

El país se ha hecho más consciente de la necesidad de desarrollar políticas de comercio exterior más congruentes con las tendencias internacionales y, pese a la reciente crisis mundial, el gobierno central ha buscado mecanismos para sobrellevar mejor estas situaciones. Los gremios han cumplido un importante papel, ya que han adoptado medidas para diversificar sus exportaciones y sus socios comerciales favoreciendo la creación de nuevos acuerdos con otros países. Así se ha consolidado una política exterior basada en los principios del liberalismo, el respeto por el derecho internacional, la resolución pacífica de conflictos, y el recurso al diálogo y al multilateralismo (Vargas, Sosa et al., 2012).

Con respecto a la diversificación de las exportaciones cabe mencionar que algunos estudios, como los de Gutiérrez de Piñeres y Ferrantino (1999), sugieren que Colombia no ha logrado resultados importantes en esta materia, pese a que las exportaciones totales han mostrado un aumento casi continuo desde la apertura, debido en parte al comportamiento favorable de la tasa de cambio. De modo que este rubro no es aún una fuente de crecimiento económico.

Con respecto a la diversificación de los socios comerciales, la evidencia empírica indica que se han logrado resultados (cuadro 1). Según Martincus y Gómez (2010), la concentración sectorial de las exportaciones ha sido una continua preocupación de las autoridades de política de los países en desarrollo, y muchos países han promovido la creación de acuerdos comerciales para diversificar los mercados y elevar las exportaciones. E1 tratado de libre comercio Colombia y 
Estados Unidos ha impulsado esta diversificación, pero solo hasta cierto punto, y no ha tenido los resultados esperados debido a que es imprescindible que el Estado atienda otros aspectos estratégicos relacionados con la infraestructura física, la facilitación del comercio en general, las condiciones logísticas y el mejoramiento del capital humano.

Cuadro 1

Acuerdos comerciales de Colombia para promover las exportaciones*

\begin{tabular}{|c|c|c|c|c|}
\hline Nombre & Países participantes & Tipo & Cobertura & Inicio oficial \\
\hline $\begin{array}{l}\text { Asociación Latinoamericana } \\
\text { de Integración }\end{array}$ & $\begin{array}{l}\text { Argentina, Bolivia, Brasil, } \\
\text { Chile, Colombia, Cuba, } \\
\text { Ecuador, México, Paraguay, } \\
\text { Perú, Uruguay y Venezuela }\end{array}$ & $\begin{array}{l}\text { Integración } \\
\text { económica }\end{array}$ & Bienes & $\begin{array}{l}18 \text { de marzo } \\
\text { de } 1981\end{array}$ \\
\hline Comunidad Andina (CAN) & $\begin{array}{l}\text { Bolivia, Colombia, Ecuador } \\
\text { y Perú }\end{array}$ & $\begin{array}{l}\text { Integración } \\
\text { económica }\end{array}$ & $\begin{array}{l}\text { Bienes y } \\
\text { servicios }\end{array}$ & $\begin{array}{l}25 \text { de mayo de } \\
1988\end{array}$ \\
\hline $\begin{array}{l}\text { Tratado de Libre Comercio } \\
\text { entre los Estados Unidos } \\
\text { Mexicanos y Colombia }\end{array}$ & Colombia y México & $\begin{array}{l}\text { Tratado de } \\
\text { libre comercio }\end{array}$ & $\begin{array}{l}\text { Bienes y } \\
\text { servicios }\end{array}$ & $\begin{array}{l}1 \text { de enero de } \\
1995\end{array}$ \\
\hline $\begin{array}{l}\text { Acuerdo de Libre Comercio } \\
\text { Chile-Colombia }\end{array}$ & Chile y Colombia & $\begin{array}{l}\text { Tratado de } \\
\text { libre comercio }\end{array}$ & $\begin{array}{l}\text { Bienes y } \\
\text { servicios }\end{array}$ & $\begin{array}{l}8 \text { de mayo de } \\
2009\end{array}$ \\
\hline $\begin{array}{l}\text { Acuerdo de Libre Comercio } \\
\text { entre Colombia y los Estados } \\
\text { AELC }\end{array}$ & $\begin{array}{l}\text { Colombia, Suiza, Liechten- } \\
\text { stein, Noruega e Islandia }\end{array}$ & $\begin{array}{l}\text { Tratado de } \\
\text { libre comercio }\end{array}$ & $\begin{array}{l}\text { Bienes y } \\
\text { servicios }\end{array}$ & $\begin{array}{l}1 \text { de julio de } \\
2011\end{array}$ \\
\hline $\begin{array}{l}\text { Acuerdo de Promoción } \\
\text { Comercial entre Colombia y } \\
\text { Canadá }\end{array}$ & Colombia y Canadá & $\begin{array}{l}\text { Tratado de } \\
\text { libre comercio }\end{array}$ & $\begin{array}{l}\text { Bienes y } \\
\text { servicios }\end{array}$ & $\begin{array}{l}15 \text { de agosto } \\
\text { de } 2011\end{array}$ \\
\hline Alianza del Pacífico & $\begin{array}{l}\text { Chile, Colombia, México } \\
\text { y Perú }\end{array}$ & $\begin{array}{l}\text { Integración } \\
\text { económica }\end{array}$ & $\begin{array}{l}\text { Bienes y } \\
\text { servicios }\end{array}$ & $\begin{array}{l}1 \text { de mayo de } \\
2016\end{array}$ \\
\hline $\begin{array}{l}\text { Tratado de Libre Comercio } \\
\text { entre Colombia y El Salvador, } \\
\text { Guatemala y Honduras }\end{array}$ & $\begin{array}{l}\text { Colombia, E1 Salvador, } \\
\text { Guatemala y Honduras }\end{array}$ & $\begin{array}{l}\text { Tratado de } \\
\text { libre comercio }\end{array}$ & $\begin{array}{l}\text { Bienes y } \\
\text { servicios }\end{array}$ & $\begin{array}{l}12 \text { de noviem- } \\
\text { bre de } 2009\end{array}$ \\
\hline $\begin{array}{l}\text { Acuerdo de Promoción } \\
\text { Comercial entre Colombia y } \\
\text { Estados Unidos }\end{array}$ & Colombia y Estados Unidos & $\begin{array}{l}\text { Tratado de } \\
\text { libre comercio }\end{array}$ & $\begin{array}{l}\text { Bienes y } \\
\text { servicios }\end{array}$ & $\begin{array}{l}15 \text { de mayo de } \\
2012\end{array}$ \\
\hline $\begin{array}{l}\text { Acuerdo Comercial entre la } \\
\text { Unión Europea, Colombia } \\
\text { y Perú }\end{array}$ & $\begin{array}{l}\text { Colombia, Perú y Unión } \\
\text { Europea }\end{array}$ & $\begin{array}{l}\text { Tratado de } \\
\text { libre comercio }\end{array}$ & $\begin{array}{l}\text { Bienes y } \\
\text { servicios }\end{array}$ & $\begin{array}{l}1 \text { de marzo de } \\
2013\end{array}$ \\
\hline $\begin{array}{l}\text { Acuerdo de Libre Comercio } \\
\text { entre Colombia y Corea }\end{array}$ & Colombia y Corea del Sur & $\begin{array}{l}\text { Tratado de } \\
\text { libre comercio }\end{array}$ & $\begin{array}{l}\text { Bienes y } \\
\text { servicios }\end{array}$ & $\begin{array}{l}15 \text { de julio de } \\
2016\end{array}$ \\
\hline $\begin{array}{l}\text { Tratado de Libre Comercio } \\
\text { entre Colombia y Costa Rica }\end{array}$ & Colombia y Costa Rica & $\begin{array}{l}\text { Tratado de } \\
\text { libre comercio }\end{array}$ & $\begin{array}{l}\text { Bienes y } \\
\text { servicios }\end{array}$ & $\begin{array}{l}1 \text { de agosto de } \\
2016\end{array}$ \\
\hline
\end{tabular}

* Solo se incluyen los acuerdos comerciales con otros países o bloques comerciales registrados ante la OMC. No se incluyen el acuerdo comercial de la CAN de la que Colombia forma parte, el Mercosur ni el Caricom, el último de los cuales no figura en la base de datos de la OMC.

Fuente: OMC (2017) y MINCIT (2017), elaboración propia.

Para potenciar el comercio exterior se debe promover el mercado interno y dar a conocer la oferta de producción local, para atraer inversión extranjera que fomente los sectores más estratégicos y favorezca las exportaciones. Para ello es imprescindible que el Estado garantice unas condiciones sociales mínimas a los actores interesados, principalmente las empresas, para que puedan incursionar en los mercados internacionales (Cardona, 2001). 
Según Martínez (2007), se ha adoptado una serie de medidas puntuales para promover las exportaciones colombianas, teniendo en cuenta las limitaciones de su aparato productivo, cuyas desventajas frente a los competidores internacionales son evidentes. La promoción de exportaciones es hoy una política prioritaria de los gobiernos de países desarrollados y en proceso de industrialización como sucede en Colombia y se muestra en el cuadro 2.

\section{Cuadro 2}

Algunas políticas de comercio exterior para la promoción de exportaciones

\begin{tabular}{|c|c|c|c|}
\hline Nombre & Definición & Normativa & Fuente \\
\hline $\begin{array}{l}\text { Promoción de expor- } \\
\text { taciones }\end{array}$ & $\begin{array}{l}\text { Agiliza los trámites del Registro Nacional de } \\
\text { Exportadores y de expedición de Certificados de } \\
\text { Origen. A través de estos documentos se puede } \\
\text { solicitar la devolución del IVA, la exención de } \\
\text { ciertos impuestos, la utilización de programas } \\
\text { aduaneros especiales, otorgamiento de créditos } \\
\text { entre otros beneficios. }\end{array}$ & $\begin{array}{l}\text { Ley Marco } 7 \\
\text { de } 1991\end{array}$ & $\begin{array}{c}\text { (MINCIT, } \\
\text { 2017) }\end{array}$ \\
\hline Plan Vallejo & $\begin{array}{l}\text { Permite reclamar la totalidad de aranceles para } \\
\text { aquellas materias primas importadas empleadas } \\
\text { para elaborar productos manufacturados en Co- } \\
\text { lombia con destino hacia otros países. Actualmente } \\
\text { esta medida representa un gran ahorro de dinero } \\
\text { ya que este proceso representa una disminución } \\
\text { significativa de los costos de producción. }\end{array}$ & $\begin{array}{c}\text { Decreto } \\
444 \text { de } 1967 \\
\text { Decreto } \\
2331 \text { de } 2001\end{array}$ & $\begin{array}{l}\text { (Banrep, } \\
\text { 2017) }\end{array}$ \\
\hline $\begin{array}{l}\text { Certificado de Re- } \\
\text { embolso Tributario } \\
\text { (CERT) }\end{array}$ & $\begin{array}{l}\text { Instrumento que hace posible la promoción a las } \\
\text { exportaciones por medio de la devolución total o } \\
\text { parcial de impuestos indirectos u otros impuestos } \\
\text { pagados por los exportadores, dentro de las opera- } \\
\text { ciones de producción y/o comercialización de los } \\
\text { productos vendidos al exterior. Este mecanismo } \\
\text { fue bastante popular no obstante en la actualidad } \\
\text { se encuentra inactivo. }\end{array}$ & $\begin{array}{l}\text { Decreto } 446 \\
\text { de } 1992 \\
\text { Decreto } 955 \\
\text { de } 1996\end{array}$ & $\begin{array}{l}\text { (Banrep, } \\
\text { 2017) }\end{array}$ \\
\hline $\begin{array}{l}\text { Comercializadoras } \\
\text { internacionales }\end{array}$ & $\begin{array}{l}\text { Facilita el acceso a las líneas de crédito de Bancoldex } \\
\text { además de permitir el acceso directo a los sistemas } \\
\text { especiales de importación exportación. Obtener } \\
\text { la exención del IVA y del impuesto de retención } \\
\text { en la fuente todo ello por la venta de productos } \\
\text { colombianos al exterior. }\end{array}$ & $\begin{array}{l}\text { Decreto } 2766 \\
\text { de } 2012 \\
\text { Resolución } \\
009 \text { de } 2013\end{array}$ & $\begin{array}{c}\text { (Procolombia, } \\
\text { 2017) }\end{array}$ \\
\hline Zonas francas & $\begin{array}{l}\text { Atraer inversión extranjera, impulsar las exporta- } \\
\text { ciones, generar empleo, lograr transferencia tec- } \\
\text { nológica y promover el desarrollo de las regiones } \\
\text { por medio de un área geográfica delimitada con } \\
\text { un régimen aduanero especial. }\end{array}$ & $\begin{array}{l}\text { Decreto } 918 \\
\text { de mayo de } \\
\quad 2001 \\
\text { Decreto } 2147 \\
\quad \text { de } 2016\end{array}$ & $\begin{array}{l}\text { (MINCIT, } \\
\text { 2017) }\end{array}$ \\
\hline $\begin{array}{l}\text { Regionalización de la } \\
\text { oferta exportable }\end{array}$ & $\begin{array}{l}\text { Promueve la cultura exportadora a través de cuer- } \\
\text { pos constituidos por representantes de los sectores } \\
\text { privado y público, facilitando su desarrollo incen- } \\
\text { tivando la vocación exportadora regional. }\end{array}$ & $\begin{array}{l}\text { Decreto } 2350 \\
\text { de } 1991\end{array}$ & $\begin{array}{l}\text { (MINCIT, } \\
\text { 2017) }\end{array}$ \\
\hline
\end{tabular}

Fuente: Banrep (2017), elaboración propia.

Llama la atención que si bien Colombia ha adoptado políticas y normas para promover la creación de organismos puntuales, así como programas especiales para fomentar iniciativas que potencien las exportaciones, no hayan funcionado a cabalidad. Pues no se ha logrado diversificar y aumentar efectivamente las exportaciones de sectores 
diferentes a la minería. Aparte de otros inconvenientes, las normas que promueven estas iniciativas, en algunos casos son poco claras y e insuficientes para los empresarios que intentan exportar (Gómez, Martínez y Arzuza, 2006).

Es claro que la diversificación de las exportaciones colombianas y, sobre todo, el aumento del número de productos de exportación; son bastante limitados. Algunos estudios muestran que la industria exportadora no ha avanzado mientras que las importaciones crecen y se diversifican sus proveedores, es decir, aumenta el número de países que exportan al país (Argüello, 2017). Quizá por ello, Torres (2014) argumenta que desde la apertura económica no ha habido cambios significativos en el entramado industrial exportador del país. La inversión en infraestructura, las exportaciones industriales, las tasas de educación y otros aspectos muestran pocos resultados. La principal fuente de divisas proviene es en esencia la exportación de bienes de consumo tradicionales y mineros. El saldo de la balanza comercial agrava este panorama porque Colombia importa principalmente productos industriales, que en su mayoría no produce, lo que le impide generar excedentes suficientes para invertir y desarrollar el aparato productivo, en especial cuando hay cambios súbitos en los precios externos. Además, las importaciones han aumentado notablemente, sobre todo las procedentes de China, y este es un reto que hoy se debe enfrentar.

Los problemas del sector industrial colombiano son graves y aún no es factible lograr las metas de competitividad e inserción a los mercados externos. En primer lugar, por la falta de sofisticación de los productos, es decir, la escasa producción de bienes con alto valor agregado. En segundo lugar, por los problemas del uso creciente del conocimiento científico y tecnológico; y en tercer lugar, por la incapacidad para consolidar la cultura de innovación. Ante esos problemas las simples políticas de comercio exterior no han sido suficientes para una transformación productiva que hagan posible un cabal crecimiento y el bienestar social (Montoya, 2011).

Con respecto a la competitividad en general algunos autores, como Duranton (2015), destacan que posiblemente sea uno de los aspectos más trascendentales para el comercio exterior del país dadas las grandes distancias entre las principales ciudades y la deficiente infraestructura vial es determinante en sus intercambios; de modo que hoy es un gran obstáculo más para el crecimiento económico.

En el sector agrícola, que debería tener una alta competitividad por la disponibilidad de recursos y la dotación de factores relativamente 
abundantes, existen retos importantes. Los problemas del sector y de las zonas rurales constituyen un gran desafío institucional, y se requieren políticas integrales que diversifiquen efectivamente la producción agrícola y, con ello, las exportaciones, en un marco institucional estable y participativo (Ropero-B, 2016).

\section{METODOLOGÍA}

Para construir un marco teórico sólido se consultaron bases de datos de revistas científicas de alto impacto científico como Web of Science (WOS) y Scopus, así como Science Direct, Ebsco, Doaj, Scielo y afines, donde se rastrearon artículos cuyas palabras clave fueran "comercio exterior colombiano, comercio internacional, exportaciones y balanza comercial", entre otras. También se rastrearon en idioma inglés para aumentar el número de artículos y se consideraron trabajos en línea publicados por google books y google scholar para enriquecer el material bibliográfico relacionado con el tema. Todo el material bibliográfico se condensó en fichas bibliográficas que hicieron posible elaborar, para cada artículo y fuente de consulta, un esquema y un compendio de las ideas centrales para su adecuada referenciación. Esta fue la base para hacer una revisión sistémica que identificara los aportes teóricos más relevantes, teniendo en cuenta su impacto por número de citas y su reconocimiento académico, la cual da consistencia al marco teórico del artículo (Amat y Rocafor, 2017).

Para obtener los resultados se consultaron las páginas web del International Trade Centre (ITC), la Dirección de Impuestos y Aduanas Nacionales de Colombia (Dian), el Departamento Administrativo Nacional de Estadística (Dane) y el Ministerio de Comercio, Industria y Turismo, así como páginas de otras fuentes confiables para acopiar los datos del periodo de estudio -1995-2016- que se analizan y se presentan en los cuadros y gráficos de este estudio de caso. El estudio de caso es una técnica de investigación que permite analizar un fenómeno concreto considerando sus particularidades y sus complejidades en un contexto más amplio y relevante, empleando métodos cualitativos, cuantitativos o mixtos que permiten ir más allá de la descripción para llegar a una mejor comprensión del fenómeno (Simons, 2009; Rusell, Greenhalgh y Kushner, 2015).

\section{RESULTADOS}

En 2016 se registraron 11.155 empresas que exportaron mercancías a los mercados internacionales por una valor de 31.095 millones de 
dólares. No obstante, las primeras cinco empresas, dedicadas a la minería, exportaron el 34,2\%, algo más de 10.634 millones de dólares (cuadro 3). Las exportaciones de las principales empresas mineras de la lista aportan un 46\% de las exportaciones totales, algo más de 14.552 millones de dólares. La principal empresa exportadora no minera es la Federación Nacional de Cafeteros de Colombia, que aporta el 2,1\% del total, 663,2 millones de dólares.

Cuadro 3

Empresas con mayor participación en las exportaciones del país (Miles de dólares)

\begin{tabular}{rlccc}
\hline $\mathbf{N}^{\circ}$ & Razón social exportador & Producto & Valor & $\%$ \\
\hline 1 & Ecopetrol S.A. & Minería & $5.951,4$ & 19,1 \\
2 & Drummond Ltd. & Minería & $1.552,5$ & 5,0 \\
3 & Refinería de Cartagena S.A. & Minería & $1.142,0$ & 3,7 \\
4 & C.I. Prodeco S.A. & Minería & $1.063,9$ & 3,4 \\
5 & Carbones del Cerrejón Limited & Minería & 924,9 & 3,0 \\
6 & Federación Nacional de Cafeteros de Colombia & Café & 663,1 & 2,1 \\
7 & Meta Petroleum Corp & Minería & 549,5 & 1,8 \\
8 & Cerrejón Xona Norte S.A. & Minería & 537,9 & 1,7 \\
9 & C.I. J. Gutiérrez y CIA S.A. & Minería & 517,1 & 1,7 \\
10 & C.I. Unión de Bananeros de Urabá S.A. & Bananos & 397,1 & 1,3 \\
11 & Polipropileno del Caribe S.A. & Plásticos & 361,9 & 1,2 \\
12 & Equin Energía Ltd. & Minería & 346,4 & 1,1 \\
13 & Occidental Andina & Minería & 344,1 & 1,1 \\
14 & Petrominerales & Minería & 339,1 & 1,1 \\
15 & Sofasa & Automóviles & 337,6 & 1,1 \\
16 & Cerro Matoso S.A. & Minería & 327,7 & 1,1 \\
17 & Colombina S.A. & Confitería & 266,2 & 0,9 \\
18 & Organización Terpel S.A. & Minería & 254,2 & 0,8 \\
19 & Mexichem resinas Colombia SAS. & Plásticos & 240,2 & 0,8 \\
20 & Carcafé Ltda. & Café & 235,8 & 0,8 \\
21 & Bayer & Insecticidas & 231,9 & 0,7 \\
22 & Hocol & Minería & 207,8 & 0,7 \\
23 & Comercializadora de metales preciosos & Minería & 202,3 & 0,7 \\
24 & Rafael Espinosa hermanos \& CIA SCA sucesores & Café & 200,6 & 0,6 \\
25 & Occidental de Colombia, LLC & Minería & 191,1 & 0,6 \\
Demás empresas & Otros & $1.3707,1$ & 44,1 \\
Total & & $31.095,1$ & 100,0 \\
\hline
\end{tabular}

Fuente: Dian (2017), elaboración propia.

Entre otras empresas no mineras se destacan la Unión de Bananeros de Urabá, con el 1,3\% del total, algo más de 397,2 millones de dólares; la Sociedad de Fabricación de Automotores (Sofasa) con el 1,1\% de las exportaciones totales, 337,7 millones de dólares; y Colombina con el 0,9\% del total, 266,2 millones de dólares.

Por su parte, los departamentos de Colombia con mayores exportaciones por declaraciones efectuadas de tráfico de mercancías, incluidos minería, petróleo y sus derivados (gráfica 1), son Cundinamarca, An- 
tioquia y La Guajira, que aportan casi la mitad de las exportaciones del país, el 50,3\%, unos 15.640 millones de dólares.

Gráfica 1

Exportaciones por departamento

(Millones de dólares)

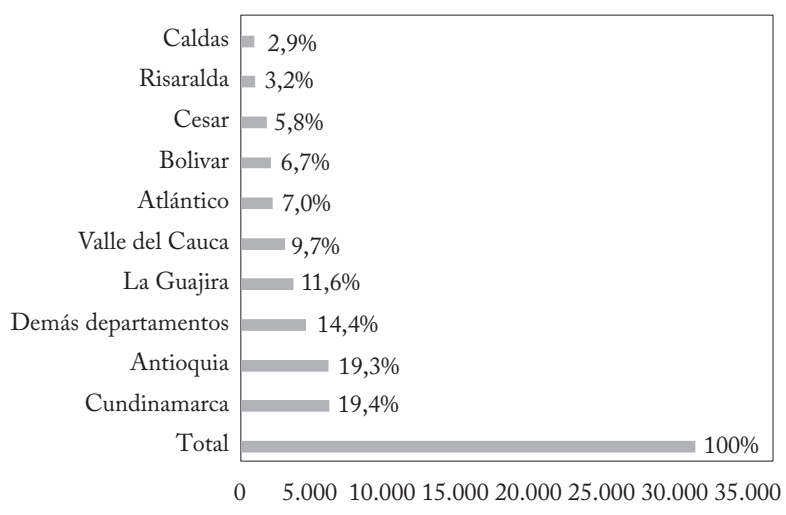

Fuente: Dian (2017), elaboración propia.

Cundinamarca es el principal departamento exportador, con el 19,4\% del total (6.032 millones de dólares), seguido con muy poca diferencia por Antioquia, con el 19,3\% (6.001 millones de dólares) y La Guajira, con el 11,6\% (3.607 millones de dólares). Después viene el Valle del Cauca (9,7\%, 3.016 millones de dólares), Atlántico (7\%, 2.176 millones de dólares), Bolívar (6,7\%, 2.083 millones de dólares), Cesar (5,8, 1.803 millones de dólares), Risaralda (3,2\%, 995 millones de dólares) y Caldas (2,9\%, 901 millones de dólares). Los demás departamentos aportan el 14,4\%, 4.481 millones de dólares.

Los flujos comerciales de salida por tipo de productos (gráfica 2) muestran un panorama similar al de las exportaciones por empresas. Los productos mineros cubren casi la mitad de las exportaciones del país, seguidos por el café, las flores, el banano y otros más. La minería aporta el 47,2\% (14.689 millones de dólares), el café el 7,92\% (2.462 millones de dólares); las flores el 4,2\% (1.312 millones de dólares), el plástico el 4,11\% (1.278 millones de dólares) y el banano el 2,94 (914 millones de dólares); la confitería, los insecticidas y los automóviles aportan el $1,7 \%$, el $1,4 \%$ y el $1,27 \%$, respectivamente. Porcentajes correspondientes a un total de 31.095 millones de dólares.

En cuanto al destino de las exportaciones (gráfica 3), el principal país comprador es Estados Unidos, que compra casi un tercio del total, el 32,2\% (10.023 millones de dólares); le siguen Ecuador, con el 3,9\% 
(1.200 millones de dólares); Perú, con un 3,4\% (1.052 millones de dólares); México con un 3,0\% (937 millones de dólares); Venezuela, con un 2,0\% (614 millones de dólares). Luego vienen Alemania, con un 1,5\% (476 millones de dólares); Bélgica; con el 1,5\% (451 millones de dólares) y Japón, con el 1,48\% (428 millones de dólares).

\section{Gráfica 2}

Productos colombianos más exportados en la actualidad (Porcentaje)

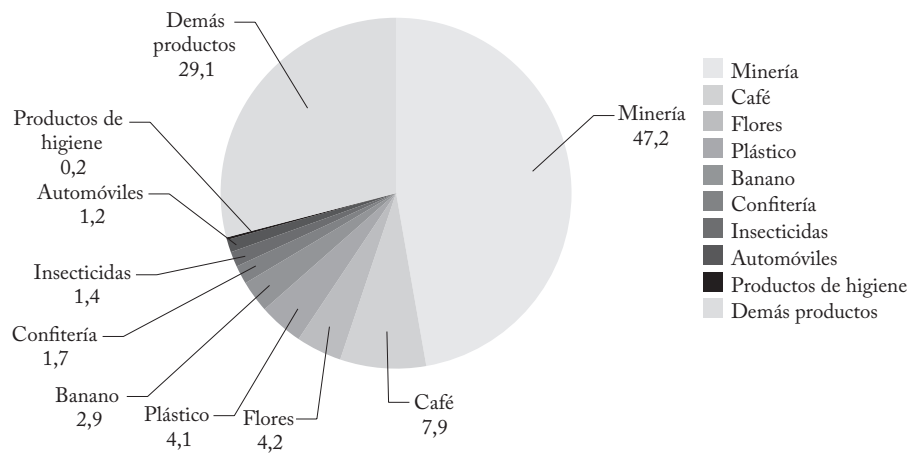

Fuente: ITC (2017) y Dian (2017), elaboración propia.

Gráfica 3

Exportaciones por país comprador

(Miles de millones de dolares)

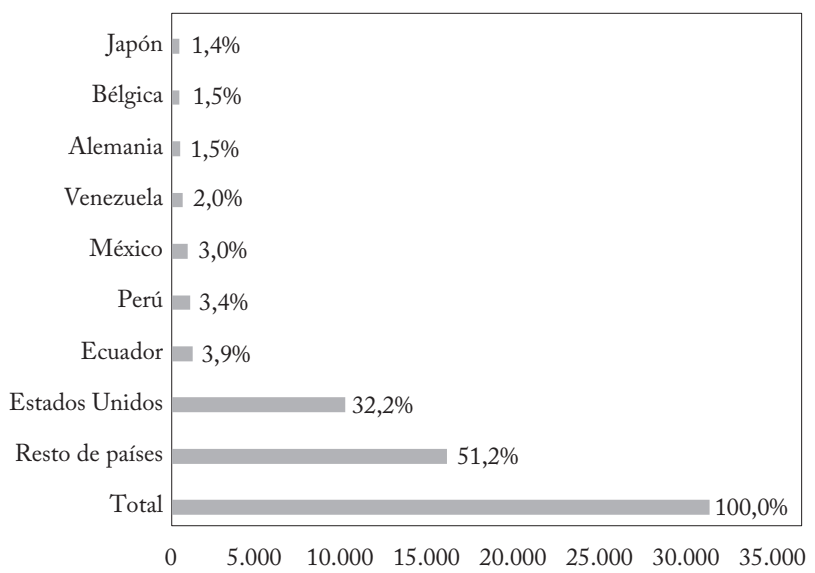

Fuente: Dane (2017), elaboración propia.

Por su parte, el valor de las exportaciones totales (gráfica 4) viene experimentando un alarmante descenso, después del pico de 2012, 
cuando llegó a 60.125 millones de dólares, liderado por la minería, que fue seguida por la industria y la agricultura.

\section{Gráfica 4}

Comportamiento de las exportaciones colombianas

(Millones de dólares)

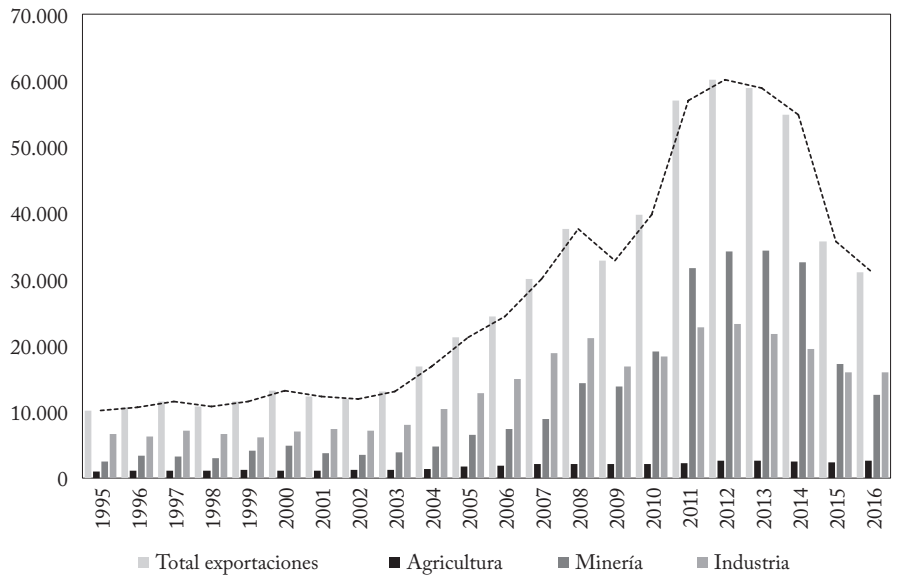

Fuente: Dane (2017), elaboración propia.

Gráfica 5

Exportaciones en años clave

(Millones de dólares)

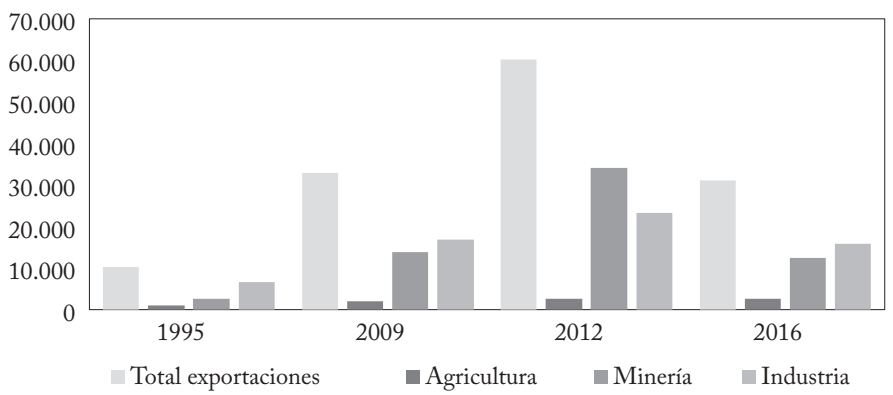

Fuente: Dane (2017), elaboración propia.

Como se observa en las gráficas 4 y 5, desde la inserción de Colombia al sistema multilateral de comercio como miembro oficial de la OMC, pasó de exportar 10.201 millones de dólares en 1995 a 37.626 millones de dólares en 2008, con un crecimiento casi ininterrumpido. Las exportaciones se redujeron a 32.846 millones de dólares en 2009 por los efectos de la crisis mundial, luego se recuperaron hasta llegar 
a 60.125 millones de dólares en 2012, cuando alcanzaron su punto más alto, como ya se mencionó, y después sufrieron un pronunciado declive hasta 31.095 millones de dólares en 2016, un nivel inferior al que se registró durante la crisis mundial.

De acuerdo con el análisis anterior, el comercio exterior colombiano y en particular las exportaciones han experimentado cuatro momentos estratégicos: 1) el inicio de la apertura económica y el ingreso como miembro oficial de Colombia a la OMC en 1995; 2) la caída de las exportaciones provocada por la crisis económica mundial de 2009; 3) la recuperación y el punto más alto de las exportaciones en 2012; y 4) la estrepitosa caída de las exportaciones en 2016.

Cuadro 4

Participación de Colombia en la exportación de productos mineros (Dólares)

\begin{tabular}{llrrr}
\hline $\begin{array}{c}\text { Posición } \\
\text { mundial }\end{array}$ & \multicolumn{1}{c}{ Producto } & $\begin{array}{c}\text { Valor de las } \\
\text { exportaciones } \\
\text { colombianas }\end{array}$ & $\begin{array}{c}\text { Participación } \\
\text { porcentual }\end{array}$ & $\begin{array}{c}\text { Valor de las } \\
\text { exportaciones } \\
\text { mundiales }\end{array}$ \\
\hline 4 & Ferroníquel & 327.765 .000 & 11,2 & 2.940 .128 .000 \\
5 & Carbón & 4.392 .669 .000 & 5,9 & 74.400 .697 .000 \\
11 & Abonos minerales & 102.033 .000 & 2,3 & 4.446 .251 .000 \\
15 & Piedras preciosas & 10.185 .000 & 1,0 & 1.007 .573 .000 \\
21 & Aceites de petróleo & 8.000 .913 .000 & 1,4 & 677.789 .460 .000 \\
28 & Oro & 1.519 .875 .000 & 0,5 & 324.601 .664 .000 \\
\hline
\end{tabular}

Fuente: ITC (2017), elaboración propia.

Un análisis más detallado de la participación de las exportaciones de materias mineras muestra que, pese a la fuerte dependencia de este tipo de productos, Colombia no ocupa un papel tan destacado en comparación con otros países, excepto en las exportaciones de ferroníquel y carbón, en las que Colombia es uno de los cinco principales países exportadores del mundo. Como muestra el cuadro 4 la participación del ferroníquel en las exportaciones mundiales es del 11,2\% y la del carbón del 5,9\%, y Colombia ocupa las posiciones cuarta y quinta en el comercio internacional. Otras materias primas y productos si bien no ocupan las diez primeras posiciones también tienen una participación interesante, como los abonos minerales, con un 2,3\%; las piedras preciosas, con el 1\%; los aceites de petróleo, con el 1,4\%; y el oro, con un 0,5\%; entre 193 países.

La participación de algunas materias primas agrícolas en las de las exportaciones mundiales (cuadro 5) muestra un abierto contraste, pues aunque su participación en las exportaciones totales del país es relativamente baja, ocupan lugares destacados a nivel mundial, y al menos en cinco productos Colombia figura entre los principales exportadores 
a nivel mundial. Como muestra el cuadro 5 la participación de las flores es del 17,0\%, la del café del 8,1\% y la del banano del 8,25\%, que se sitúan entre las cinco primeras posiciones de las exportaciones mundiales: la segunda, la tercera y la cuarta respectivamente. Otros dos productos ocupan la sexta posición: la caña de azúcar con el 2,3 y el aceite de palma con el 2,8\%. El aguacate, con el 0,8\% ocupa el décimo quinto lugar.

Cuadro 5

Participación de Colombia en la exportación de productos agrícolas (Dólares)

\begin{tabular}{llrcr}
\hline $\begin{array}{l}\text { Posición } \\
\text { mundial }\end{array}$ & \multicolumn{1}{c}{ Producto } & $\begin{array}{c}\text { Valor de las } \\
\text { exportaciones } \\
\text { colombianas }\end{array}$ & $\begin{array}{c}\text { Porcentaje de } \\
\text { participación }\end{array}$ & $\begin{array}{c}\text { Valor de las } \\
\text { exportaciones } \\
\text { mundiales }\end{array}$ \\
\hline 2 & Flores & 1.312 .262 .000 & 17,0 & 7.704 .217 .000 \\
3 & Café & 2.526 .532 & 8,1 & 30.512 .682 .000 \\
4 & Banano & 914.937 .000 & 8,4 & 11.087 .590 .000 \\
6 & Caña de azúcar & 6.096 .000 & 2,3 & 263.256 .000 \\
6 & Aceite de palma & 208.586 .000 & 2,8 & 7.335 .917 .000 \\
15 & Aguacate & 35.040 .000 & 0,8 & 4.404 .496 .000 \\
\hline
\end{tabular}

Fuente: ITC (2017), elaboración propia.

El cuadro 6 muestra la participación en las exportaciones mundiales de otros productos que se sitúan en las primeras cincuenta posiciones. Los insecticidas, con el 2,7\%; la confitería, con el 2,4\%; y las estructuras de metal, con el 1,4\%; los cuales ocupan las posiciones décima, décimo segunda y décimo octava, respectivamente. Los productos de higiene, con el 0,4\%; los plásticos, con el 1,0\%; y los automóviles, con apenas el 0,1 , se ubican en las posiciones vigésimo primera, vigésimo carta y cuadragésimo segunda, respectivamente.

Cuadro 6

Participación de Colombia en la exportación mundial de bines industriales (Dólares)

\begin{tabular}{llcrr}
\hline $\begin{array}{l}\text { Posición } \\
\text { mundial }\end{array}$ & \multicolumn{1}{c}{ Producto } & $\begin{array}{c}\text { Valor de las } \\
\text { exportaciones } \\
\text { colombianas }\end{array}$ & $\begin{array}{c}\text { Porcentaje de } \\
\text { participación }\end{array}$ & $\begin{array}{c}\text { Valor de las } \\
\text { exportaciones } \\
\text { mundiales }\end{array}$ \\
\hline 10 & Insecticidas & 202.719 .000 & 2,7 & 7.397 .684 .000 \\
12 & Confitería & 250.702 .000 & 2,4 & 10.602 .500 .000 \\
18 & Estructuras de metal & 156.362 .000 & 1,4 & 11.347 .088 .000 \\
21 & Productos de higiene & 70.378 .000 & 0,4 & 16.373 .380 .000 \\
24 & Plásticos & 351.254 .000 & 1,0 & 36.842 .415 .000 \\
42 & Automóviles & 336.164 .000 & 0,1 & 275.592 .610 .000 \\
\hline
\end{tabular}

Fuente: ITC (2017), elaboración propia. 


\section{CONCLUSIONES}

La política de comercio exterior colombiana ha llevado a que en los últimos años se haya creado una fuerte dependencia de la extracción de materias primas mineras, en menoscabo de los productos industriales que generan mayor valor agregado. En términos de origen geográfico, los departamentos de Cundinamarca, Antioquia, La Guajira y Valle del Cauca son los principales exportadores y aportan un $60 \%$ de las exportaciones totales.

Pese al fuerte descenso de las exportaciones totales, las materias primas mineras ocupan un lugar preponderante en el comercio exterior del país, pues aportan el 47,2\% de las exportaciones totales, aunque no ocupen las primeras posiciones dentro de las exportaciones mundiales, excepto el ferroníquel y el carbón que aportan el 11,1\% y el $5,9 \%$, respectivamente. En cambio, las flores, el café y el banano que en conjunto solo aportan el 15\% de las exportaciones totales del país, ocupan altas posiciones mundiales, con participaciones del 17,0\%, $8,1 \%$ y $8,3 \%$, respectivamente.

Entre los países destinatarios de las exportaciones colombianas, Estados Unidos ocupa el primer lugar, con el 32,2\% del total. Los principales socios comerciales latinoamericanos -Ecuador, Perú, México y Venezuela- compran menos de la mitad que Estados Unidos, el $12,2 \%$.

$\mathrm{E}$ incremento de los precios internacionales del petróleo y de algunos minerales entre 2010 y 2015 aumentó la participación del sector primario en la exportaciones en ese lustro; en todos esos años aportó más de la mitad de las exportaciones del país, con una participación máxima del 59,4\% en 2014.

Aunque las participaciones más recientes se han modificado, pues las exportaciones mineras se redujeron al $44,9 \%$ frente al $47,2 \%$ del sector industrial en 2016, eso no significa que el valor y la participación de las exportaciones de bienes industriales hayan aumentado debido a una industrialización efectiva. E1 cambio de las participaciones fue provocado simplemente por la caída del precio de internacional de las materias mineras; $y$ cabe precisar que el valor de las exportaciones industriales se redujo de 22.772 millones de dólares en 2011, su punto más alto, a 15.956 en 2016.

El país y su política de comercio exterior hoy afrontan un momento crítico, debido al deterioro de los términos de intercambio, no solo por la fuerte reducción de las exportaciones totales sino, especialmente, por la reducción de las exportaciones industriales que no han 
experimentado cambios significativos en los precios internacionales, y curiosamente en un contexto de fuerte revaluación de la divisa, que debería de haber estimulado sus exportaciones.

Es imprescindible adoptar políticas y medidas efectivas en el corto plazo que recuperen y diversifiquen las exportaciones del país, para ayudar a enfrentar los retos de la reforma rural integral y el déficit fiscal pese a las tensiones dentro del sistema político.

\section{REFERENCIAS BIBLIOGRÁFICAS}

Amat, O. y Rocafor, A. (2017). Cómo investigar. Tesis Doctoral. Barcelona: Profit Editorial.

Argüello, R. (2017). Trade diversification in Colombia, 1991-2011. Cuadernos de Economía, 36(71), 345-378.

Baena, J. y Fernández, X. (2016). Aproximaciones a la inserción de Colombia en el sistema multilateral de comercio en 1995-2015. Análisis Politico, 29(87), 114-131.

Banrep. (2017). Certificado de Reembolso Tributario (CERT), [http:// www.banrepcultural.org/blaavirtual/economia/industrilatina/164.htm].

Banrep. (2017). Plan Vallejo, [http://www.banrepcultural.org/blaavirtual/ ayudadetareas/economia/plan_vallejo].

Banrep. (2017). Visión estratégica de la política de comercio exterior, [http://www.banrepcultural.org/blaavirtual/ciencias/sena/cursos-decapacitacion/politicanal/politica16.htm].

Cardona, D. (2001). La política exterior de la administración Pastrana (1998-2002). Colombia Internacional, 53(1), 53-74.

Cruz, E. (2010). La Constitución Política de 1991 y la apertura económica. Investigación y reflexión, XVIII(1), 269-280.

Dane. (2017). Comercio Exterior - Exportaciones, [https://www.dane.gov. co/files/investigaciones/boletines/exportaciones/bol_exp_ene16.pdf].

Dane. (2017). Exportaciones, [http://www.dane.gov.co/index.php/estadisticas-por-tema/comercio-internacional/exportaciones].

Dian. (2017). Directorio de importadores y exportadores, [http://www. dian.gov.co/Dian/14CifrasGestion.nsf/e7f1561e16ab32b105256f0e00 741478/6bd6a0a2ab2bf31e05257360007ed9a9?OpenDocument].

Díaz, V. (2014). ¿Se cumple la teoría neoclásica del comercio internacional? E1 caso de la economía colombiana entre 1980 y 2007? Sociedad y Economia, 1(27), 177-206.

Duranton, G. (2015). Roads and trade in Colombia. Economics of Transportation, 4(1-2), 16-36.

Garay, L. (1998). Colombia: estructura industrial e internacionalización 1967-1996. Bogotá: DNP-Colciencias.

Gómez, L., Martinez, J. et al. (2006). Política pública y creación de empresas en Colombia. Pensamiento E Gestión, 1(21), 1-25.

Gutiérrez de Piñeres, S. y Ferrantino, M. (1999). Export sector dynamics and domestic growth: The case of Colombia. Review of Development Economics, 3(3), 268-280. 
ITC. (2017). International trade in goods - Exports 2001-2016, [http:// www.intracen.org/itc/market-info-tools/statistics-export-productcountry/].

Jacobs, J. (2015). From boom to bust for Latin America. Petroleum Economist, 82(1), 40-43.

Juárez, C. (1993). Trade and development policies in Colombia: Export promotion and outward orientation, 1967-1992. Studies in comparative international development, 28(3), 67-97.

Londoño, C. (1998). La apertura económica en Colombia. Pensamiento Humanista, 1(4), 39-51.

López, D., López, E. et al. (2015). Colombia en el comercio mundial (1992-2012): desempeño de las exportaciones colombianas. Borradores de Economía, 1(885), 1-60.

López-A., H. y Montoya-G., W. (2016). Análisis de la política de transformación productiva colombiana, basada en la incorporación de la ciencia, la tecnología y la innovación, para el mejoramiento de la competitividad de Colombia entre los años 2010 y 2014. Revista Electrónica Educare, 2O(3), 1-22.

Martincus, C. y Gómez, S. (2010). Trade policy and export diversification: What should Colombia expect from the FTA with the United States? International Trade Journal, 24(2), 100-148.

Martínez, P. (2007). Influencia de la promoción de exportaciones en el proceso del desarrollo exportador de las Pymes: Un estudio de caso. Pensamiento E̊ Gestión, 1(23), 1-57.

MINCIT. (2017). Acuerdos vigentes. Obtenido de Ministerio de Comercio Industria y Turismo, [http://www.tlc.gov.co/publicaciones/5398/ acuerdos_vigentes].

MINCIT. (2017). Comités Asesores Regionales de Comercio Exterior (CARCE). Ministerio de Comercio Industria y Turismo, [http:// www.mincit.gov.co/publicaciones/10279/comites_asesores_regionales_de_comercio_exterior_-carce-].

MINCIT. (2017). Normatividad - Zonas francas. Ministerio de Comercio Industria y Turismo, [http://www.mincit.gov.co/publicaciones/15891/ normatividad_-_zonas_francas].

MINCIT. (2017). Registro Nacional de Exportadores de Bienes y Servicios. Ministerio de Comercio Industria y Turismo, [http://www. mincit.gov.co/mincomercioexterior/publicaciones/11828/registro_nacional_de_exportadores_de_bienes_y_servicios].

Moncayo, E. (2003). Resultados de las reformas del consenso de Washington en los países andinos: estabilización incompleta, profundización de los desequilibrios sociales y crecimiento precario. Economía y Desarrollo, 2(1), 73-95.

Montoya, C. (2011). Colombia y su inserción a la economía mundial. Revista Ecos de Economia, 15(32), 172-193.

Montoya, J. (2013). The Colombian urban system in the face of globalization: Economic restructuring and regional change. Cuadernos de Vivienda y Urbanismo, 6(12), 302-320.

Ocde. (2015). Estudios económicos de la Ocde - Colombia. Ocde, [https://www.oecd.org/eco/surveys/Overview_Colombia_ESP.pdf]. 
OMC. (2017). List of notified RTAs in force. Regional trade agreements (RTA), [http://rtais.wto.org/UI/PublicSearchByMemberResult.aspx? MemberCode $=170$ \&lang $=1$ \&redirect $=1$ ] .

Ortiz, C., Uribe, J. et al. (2013). Productivity, accumulation, and other public diseconomies in the Colombian economic growth. Cuadernos de Economía, 32(59), 235-265.

Procolombia. (2017). ¿Qué es una comercializadora internacional? Turismo marca país, [http://www.colombiatrade.com.co/preguntas-frecuentes/ que-es-una-comercializadora-internacional].

Ropero-B., S. (2016). La institucionalidad rural en Colombia: reflexiones para su análisis y fortalecimiento. Mundo Agrario, 35(17), 1-13.

Rusell, J., Greenhalgh, T. et al. (2015). Case study evaluation: Past, present and future challenges. Bingley: Emerald Group Publishing Limited.

Simons, H. (2009). El estudio de caso: teoría y práctica. Madrid: Ediciones Morata.

Torres, J. (2014). Colombia: logros en dos décadas de modelo de desarrollo aperturista - Analisis según resultados de balanza comercial. Análisis Politico, 27(82), 212-235.

Unctad. (2017). Free market commodity price indices, annual, 1960-2016. United Nations Conference on Trade and Development, [http://unctadstat.unctad.org/wds/TableViewer/tableView. aspx? ReportId $=30728]$.

Vargas-A., L., Sosa, S. et al. (2012). El comercio como plataforma de la política exterior colombiana en la administración de Juan Manuel Santos. Colombia Internacional, 76(1), 259-292. 